\title{
Isotope delta challenge
}

\section{Philip J H Dunn ${ }^{1}$ (D) - Juris Meija ${ }^{2}$}

Accepted: 5 August 2021 / Published online: 11 October 2021

(C) Springer-Verlag GmbH Germany, part of Springer Nature 2021

We would like to invite you to participate in the Analytical Challenge, a series of puzzles to entertain and challenge our readers. This special feature of "Analytical and Bioanalytical Chemistry" has established itself as a truly unique quiz series, with a new scientific puzzle published every three months. Readers can access the complete collection of published problems with their solutions on the ABC homepage at http:// www.springer.com/abc. Test your knowledge and tease your wits in diverse areas of analytical and bioanalytical chemistry by viewing this collection.

In the present challenge, isotope deltas is the topic. And please note that there is a prize to be won (a Springer book of your choice up to a value of $€ 100)$. Please read on...

\section{Meet the challenge}

Isotope delta is the relative difference of isotope ratios of an element between two materials. For example, hydrogen isotope ratio, $R=N\left({ }^{2} \mathrm{H}\right) / N\left({ }^{1} \mathrm{H}\right)$, in material $\mathrm{B}$ relative to the isotope ratio in material A can be expressed as follows:

$\delta_{\mathrm{A}}\left({ }^{2} \mathrm{H}, \mathrm{B}\right)=R(\mathrm{~B}) / R(\mathrm{~A})-1$

While measurements of relative isotope ratios, isotope deltas, have been around since the 1940s, the notation surrounding this quantity still remains a hornet's nest.

While isotope delta serves as a convenient way to express small differences in isotopic composition, it comes with challenges. Consider a simple relationship between expressing

Philip J H Dunn

Philip.Dunn@1gcgroup.com

1 National Measurement Laboratory, LGC Ltd, Teddington, Middlesex TW11 0LY, UK

2 National Research Council Canada, Ottawa, ON K1A 0R6, Canada isotope ratio of $\mathrm{B}$ against $\mathrm{A}, \delta_{\mathrm{A}}(\mathrm{B})$, and expressing isotope ratio of $\mathrm{A}$ against $\mathrm{B}, \delta_{\mathrm{B}}(\mathrm{A})$. The mathematical relationship between these two quantities is obtained by noting the following:

$$
\begin{aligned}
& 1+\delta_{\mathrm{A}}\left({ }^{2} \mathrm{H}, \mathrm{B}\right)=R(\mathrm{~B}) / R(\mathrm{~A}) \\
& 1+\delta_{\mathrm{B}}\left({ }^{2} \mathrm{H}, \mathrm{A}\right)=R(\mathrm{~A}) / R(\mathrm{~B})
\end{aligned}
$$

Hence,

$$
\left[1+\delta_{\mathrm{A}}\left({ }^{2} \mathrm{H}, \mathrm{B}\right)\right] \times\left[1+\delta_{\mathrm{B}}\left({ }^{2} \mathrm{H}, \mathrm{A}\right)\right]=1
$$

This relationship can be rewritten as follows:

$$
\delta_{\mathrm{A}}\left({ }^{2} \mathrm{H}, \mathrm{B}\right)+\delta_{\mathrm{B}}\left({ }^{2} \mathrm{H}, \mathrm{A}\right)+\delta_{\mathrm{A}}\left({ }^{2} \mathrm{H}, \mathrm{B}\right) \times \delta_{\mathrm{B}}\left({ }^{2} \mathrm{H}, \mathrm{A}\right)=0
$$

This trivial example shows that, while the use of isotope deltas is convenient in practice, the calculations involving them become complicated very fast. You guessed it; this is also the topic of this challenge.

\section{The challenge}

A laboratory far, far away from here has received four natural water samples. These were creatively labelled as A, B, $\mathrm{C}$, and $\mathrm{D}$. Then, the analyst performed three comparative measurements of hydrogen isotope ratio between these samples. First, they measured sample A against sample D; then, they measured B against A, and lastly, C against B. To their surprise, the deuterium isotope delta was +250 per mille in all three cases. In other words, $\delta_{\mathrm{D}}\left({ }^{2} \mathrm{H}, \mathrm{A}\right)=+$ $250 \%$ o, $\delta_{\mathrm{A}}\left({ }^{2} \mathrm{H}, \mathrm{B}\right)=+250 \%$, and $\delta_{\mathrm{B}}\left({ }^{2} \mathrm{H}, \mathrm{C}\right)=+250 \%$. The laboratory staff can figure out what to make of these observations, but can you? 
Can you determine:

(a) Which of these materials are the most and the least enriched in deuterium (i.e., has the lowest isotope ratio R)?

(b) What is the deuterium isotope delta of the most enriched of these materials relative to the least enriched one?

\section{Declarations}

Conflict of interest The authors declare no competing interests.
We invite our readers to participate in the Analytical Challenge by solving the puzzle above. Please send the correct solution to abcchallenge@ springer.com by January 1, 2022. Make sure you enter "Isotope delta challenge" in the subject line of your e-mail. The winner will be notified by e-mail and their name will be published on the "Analytical and Bioanalytical Chemistry" homepage at http://www. springer.com/abc and in the journal (volume 414/issue 9) where readers will find the solution and a short explanation.

The next Analytical Challenge will be published in 414/1, January 2022. If you have enjoyed solving this Analytical Challenge, you are invited to try the previous puzzles on the ABC homepage.

Publisher's note Springer Nature remains neutral with regard to jurisdictional claims in published maps and institutional affiliations. 